\title{
Kuhn, Sarton, and the history of science
}

\section{J. C. Pinto de Oliveira}

Department of Philosophy, IFCH, State University of Campinas, Brazil

jcpinto@unicamp.br

Amelia J. Oliveira

Postdoctoral Fellow Researcher, IFCH, State University of Campinas - Brazil

amelijeso@gmail.com

\begin{abstract}
The scientific work of Leonardo da Vinci may have served as the main inspiration for the historical research of George Sarton. Although he never produced a work he felt was worthy of its subject, the little that he did write about Leonardo reveals the importance he attributed to him in the history of science. This is especially clear in Sarton's treatment of Leonardo and a discovery he did not make: William Harvey's discovery of blood circulation in the $17^{\text {th }}$ Century. In this article, we refer to this particular episode to trace Sarton's conception of the development of science. It is a conception that illustrates well the traditional historiographic perspective that is the target of Thomas Kuhn's criticisms. Although Kuhn never wrote about Leonardo or Harvey, we aim to show that he clearly positioned himself contrary to Sarton, albeit indirectly, with respect to this particular historical episode, as well.
\end{abstract}

Keywords: Kuhn, Sarton, Leonardo da Vinci, history of science, Butterfield, William Harvey, Galen

\section{Introduction}

In the mid-20th Century, the history of science underwent changes significant enough to speak, as did Thomas Kuhn, in terms of a "historiographic revolution" (Kuhn, 1970, p. 3). In The structure of scientific revolutions, his criticism is generally leveled against the narratives as presented in "many of the older histories of science" and "textbooks of science together with both the popularizations and the philosophical works modeled on them" (Kuhn, 1970, pp. 136 and 138). He presents a new historical perspective and cites some authors ${ }^{1}$ in the book who fomented the change, but no traditional historians,

\footnotetext{
${ }^{1}$ Alexandre Koyré, Émile Meyerson, Hélène Metzger and Anneliese Maier (Kuhn, 1970, p. vi).
} 
responsible for the books, which he argues have misled us about science "in fundamental ways" (Kuhn, 1970, p. 1).

It is only in his later writings that Kuhn's criticism is clearer with respect to the identification of followers of traditional historiography. In one of the few passages where names are cited, Kuhn refers to Condorcet, Comte, Dampier and Sarton (Kuhn, 1977, pp. 148 and 106-107). George Sarton (1884-1956) is criticized despite his significant role at the time in establishing the history of science as a discipline of study, as well as his “monumental researches" (Kuhn, 1977, pp. 109 and 148). Notwithstanding, Kuhn makes no critical reference to Sarton as representing the older history of science that is comparable to his complimentary references to Koyré as a representative of the new historiography. ${ }^{2}$ But we believe Sarton could play this role very well.

The scientific work of Leonardo da Vinci may have served as the main inspiration for Sarton's historical research. In a comparison of studies of manuscripts written by Leonardo, Sarton describes his engagement with the works of the Renaissance author:

During the years 1916-1919, I was myself engaged in a very searching analysis of the Leonardo MSS [manuscripts], delivered a series of lectures at the Lowell Institute of Boston, and then apparently dropped the subject. I did not drop it but having realized that it was impossible to appreciate correctly Leonardo's scientific thought without a deeper understanding of mediaeval thought than I then possessed, I undertook a systematic investigation of all the mediaeval writings. As my readers know, I have been engaged in that work for the last twenty-five years, and I am still a century short of Leonardo! (Sarton, 1944, p. 185).

The twenty-five years work to which Sarton refers is the "monumental" Introduction to the history of science. As Dorothy Stimson stated, this work, published in five volumes from 1927 to 1948, was the result of Sarton's effort "to make a thorough study of Leonardo da Vinci's background" (Stimson, 1962, p. xv). ${ }^{3}$

But the fact is that Sarton never achieved his goal of producing a work on Leonardo that fulfilled his own expectations. Arnold Thackray and Robert Merton (1972,

\footnotetext{
${ }^{2}$ See Pinto de Oliveira (2012).

${ }^{3}$ It is interesting to note that in 1949, the year following the publication of the last volume, Sarton speaks again of studying Leonardo and again relates it to the Introduction: "Leonardo, sometimes called the father of modern science, was the child of the Middle Ages". Therefore, to assess his thinking adequately, he believed a systematic knowledge of medieval science, "century by century", would be necessary (Sarton 1962, pp. 367-368). In the 1950s, he updated this note, referring then to his past thirty-five years of work (See Sarton, 1953a, note 3, and Sarton 1957, p. 306, note 4).
} 
p. 486) commented on his abandonment of the project aimed at the comprehensive study of Leonardo:

By 1918 [...] Sarton mentioned a study of Leonardo da Vinci's scientific manuscripts, which would take "about six months" [...] As early as July 1918 he wrote in tones of mingled consternation and delight that "Leonardo was interested in almost everything...[My book] will be in fact an encyclopedia of the positive knowledge attained at the end of the Fifteenth Century". Soon he was seeking specialist help [...] Reference to the study of Leonardo - his main concern - continues in Sarton's correspondence and annual reports for several more years, though the promised book was never to materialize (Thackray \& Merton, 1972, pp. 486-487).

Thackray and Merton (1972, p. 487) assert that Sarton published only two studies about Leonardo, "two popular studies", in 1919 and 1952 (cited here as they were republished respectively in Sarton (1948) and (1962). ${ }^{4}$ However, despite Sarton having written little about his object of inspiration, what he did write points to the importance he attributed to Leonardo in the history of science, reiterated particularly in his references to William Harvey's discovery of blood circulation in the $17^{\text {th }}$ Century.

In the present article, we seek to show how George Sarton's conception of history of science aligns itself with the traditional perspective, targeted by Kuhn in his criticisms. Avoiding the fallacy of quoting out of context, in section two we restricted ourselves to presenting conclusions centered on Leonardo's 'non-discovery' of blood circulation as a case study. ${ }^{5}$ In section three, we argue that Sarton's approach illustrates very well the 'old historiography of science', as opposed to Kuhn's "new historiography of science". Although Kuhn never wrote about Leonardo or Harvey, we aim to show that he clearly positioned himself contrary to Sarton, albeit indirectly (in Kuhn's assessment of the work of Butterfield), with respect to this particular historical episode as well.

\footnotetext{
${ }^{4}$ In addition to the studies identified by Thackray and Merton, we consider here other works by Sarton about Leonardo: the articles "Une encyclopédie léonardesque" (Sarton, 1919) and "Léonard de Vinci, ingénieur et savant" (Sarton, 1953a); two reviews of works by Leonardo organized by different editors (Sarton, 1944 and 1953b); the preface to McMurrich's book Leonardo da Vinci, the anatomist: 1452-1519 (Sarton, 1930) and Chapter 6 in Six wings: Men of science in the Renaissance (his last book, which he did not live to see published in 1957). In the 1919 article, intended to disseminate his future work on Leonardo, Sarton hints that it would be a great work composed of three parts (possibly three volumes). He said it would be entitled Leonardo: An encyclopedic survey of artistic, scientific and technical thought at the height of the Italian Renaissance and would be finished by the end of 1920 (Cf. Sarton, 1919, p. 237). We had access to the two articles in French and to the preface only when our article was practically finalized. We could still use these three texts, but consider them rather as sources that corroborate the conclusions we had already arrived at without them.

${ }^{5}$ This obviously does not signify an appreciation of Sarton's complete historical work, although the case is special and appears throughout his work. In a study that is underway, Amelia J. Oliveira seeks to understand Sarton's role in the history of science, taking into consideration a more extensive content of his work.
} 


\section{Sarton, Leonardo, and blood circulation}

In the opening lines of "The quest for truth: Scientific progress during the Renaissance", Sarton writes:

Many people misunderstand science, and hence one can hardly expect them to have a fair idea of its history. The history of science might be defined as the history of the discovery of objective truth, of the gradual conquest of matter by the human mind; it describes the agelong and endless struggle for the freedom of thought - its freedom from violence, intolerance, error, and superstition.

The history of science is one of the essential parts of the spiritual history of mankind; the other main parts are the history of art and the history of religion. It differs from these other parts in that the development of knowledge is the only development which is truly cumulative and progressive. Hence, if we try to explain the progress of mankind, the history of science should be the very axis of our explanation (Sarton, 1962, p. 102). ${ }^{6}$

The history of the discovery of blood circulation is one of the accounts Sarton presents synthetically at the beginning of The life of science as an example of this truly progressive development of knowledge. Harvey discovered that blood circulated; that it was pumped by the heart and carried to other parts of the body by the arteries and returned to the heart through the veins. Upon its return, it passed from one side of the heart to the other through the lungs where it was re-supplied with oxygen before being recirculated again.

Sarton presented Harvey's discovery as a triumph over scientists who had failed before him to discover the truth, which according to Sarton, had been within reach for a long time. This can be easily observed in Sarton's synthesis of ideas presented by Galen fourteen centuries before Harvey. Among other differences, Galen believed that blood passed from one side of the heart to the other through invisible pores directly, not via the lungs, as Harvey theorized. Sarton writes:

To explain the impossible, Galen had been obliged to assume that it [the blood] passed through innumerable invisible pores in the solid wall which

\footnotetext{
${ }^{6}$ He presents his cumulative view in a very similar way in Sarton (1927, pp. 3-4, and 1936, p. 5), passages cited often to illustrate Sarton's conception of the progress of science. See also Sarton (1937, Chapter 1).
} 
divides the right heart from the left. Nobody ever detected these pores for they are not simply invisible but nonexistent. Yet Galen, supreme pontiff of Greek medicine, and nine centuries later Avicenna, the infallible medical pope of the middle ages, had spoken ex cathedra with such indisputable authority that this gratuitous assumption was generally taken for gospel (Sarton, 1948, p. 8).

Sarton argues that ancient and medieval science lacked the parameters of modern science that resulted from the scientific revolution: the experimental method, the skeptical or critical spirit, and rationalism (Cf. Sarton, 1950, p. 155). That is why, in his view, men like Galen and Avicenna were unable to present anything other than a "gratuitous assumption" about the circulation of blood.

In the introductory chapter to his major work, Sarton declares his greater interest in modern science, being that which, according to him, accumulated more truths and presented "tremendous" progress (1927, p. 14). It is with this enthusiasm for modern science that he looks to the past:

The historian of science can not devote much attention to the study of superstition and magic, that is, of unreason, because this does not help him very much to understand human progress. Magic is essentially unprogressive and conservative; science is essentially progressive. The former goes backward; the later, forward (Sarton, 1927, p. 19).

And further on:

The amount of positive knowledge available in the Middle Ages was exceedingly small [...] There was little opportunity for induction, and knowledge, under scholastic influence, took almost exclusively a deductive form. There was not much choice; granted the arbitrary premises of the theologians and the scarcity of positive knowledge, scholasticism was almost an unavoidable consequence [...] In spite of political crises and of obscurantist tendencies, positive knowledge must increase and accumulate; every progress in that direction, be it ever so small, was final and irrevocable. Thus we may say that the cure of scholasticism was simply the progress of positive knowledge, and this means the progress of the experimental method (Sarton, 1927, pp. 23-24).

In general, the view presented in the introductory chapter of his extensive work is organized around a comparison between the "relative sterility of scholasticism" and the “immense, almost unconceivable, fertility" of modern science (Sarton, 1927, p. 28). The 
opposition between the two periods is emphasized by his repeated prescription of the experimental method for the "cure of scholasticism". 7 Sarton writes:

The history of science may always be considered under two aspects, either positively as the gradual unfolding of truth, the increase of light, or negatively as the progressive triumph over error and superstition, the decrease of darkness. The modern scientist studying mediaeval science gets a little impatient, because he is accustomed to a much faster pace; he would like to be able to watch the progress of science, and for many centuries the pace was often so slow, with so many stops and regressions, that one has the feeling that there was no progress at all (Sarton, 1927, p. 25).

This consideration by Sarton leads us back to his account of the discovery of blood circulation, in which the two aspects he cites as being components of science are clearly identifiable. Harvey's contribution was a giant step and led to rapid progress compared to the conceptions of Galen (and Avicenna) which, for many years, were, in fact, responsible for hiding the truth.

In his book about Galen (1954), Sarton then appears to complete what he believes to be the task of the science historian: on the one hand, to unveil the gradual search for the truth; on the other, present the progressive triumph over error and superstition. When he justifies the importance of Galen for modern science, he presents the contributions of the ancient anatomist, physiologist, physician, surgeon and pharmacist. ${ }^{8}$ However, according to Sarton, Galen never fully realized his potential as a scientist because

He began his life as a lover of scientific truth, an honest investigator, one of the very few ancients who understood and illustrated the experimental method, yet he ended it as a theologian. He had been carefully trained to be open-minded, impartial, and tolerant, and he preserved some kind of eclecticism in philosophy as well as in medicine, yet he created a scientific doctrine, teleology, which was as dogmatic as anything could be (Sarton, 1954, p. 59).

It is interesting to note how value-laden his historical description of this "scientific doctrine" is, which lasted for many centuries, keeping alive what Sarton refers to as "Galenic aberrations" (Sarton, 1954, p. 51). The following passage illustrates well this point of view regarding Galen:

\footnotetext{
${ }^{7}$ In addition to this passage, the expression "cure" also appears on pp. 25 and 29.

${ }^{8}$ It is interesting to note Sarton's search for Galen's contributions to areas of specialization that came to exist only after the Scientific Revolution.
} 
His description of the blood vessels was very insufficient and confusing, but who would dare blame him for that? He might have discovered the pulmonary circulation, but he did not, and his influence blocked the way for the discovery of the real circulation. Harvey himself, as late as 1628, had to be careful not to offend the prejudices and not to wound the feelings of his Galenic readers (Sarton, 1954, p. 47).

It was because of this that David Lindberg refers directly to Sarton and his Galen of Pergamon to illustrate how Galen had been the target of abuses by historians who were "angry at him for not being modern" (Lindberg, 2007, p. 130).

Modern science, according to Sarton, was a child of the Renaissance, born of those who, imbibed with the spirit of experimentation and the search for the truth, promoted a rapid expansion of knowledge (Cf. Sarton, 1948, p. 78). It is worth noting again here the article "The quest for truth", where he presents the Renaissance as the period of transition between the Middle and the Modern Ages in which the innovations were huge and revolutionary. The novelties were so numerous, according to Sarton, that it is not possible to speak of a Renaissance, since the period was truly a "real birth, a new beginning" (Sarton, 1962, p. 104).

Leonardo appears to him to be an example of the true scientific spirit: rather than indebting himself to past authorities, he observes nature; he has a critical spirit and conducts experiments. He is able to overcome the fundamental vice of the scholastics, anticipating by a century and a half, in practice, the method propagated by the philosopher Francis Bacon. These are some of the considerations presented by Sarton in the text which bears the significant title "Leonardo and the birth of modern science". 9

In "Leonardo da Vinci"10, Sarton once again provides evidence of the revolutionary aspects of the work of the great genius, precursor to so many branches of scientific knowledge, and asserts that "the historian of science is impressed by Leonardo's gadgets" (Sarton, 1962, p. 134). And from an anachronistic perspective, as pointed out by

\footnotetext{
${ }^{9}$ The 1919 text is the first of two studies by Sarton about Leonardo cited by Thackray and Merton (and republished in The life of science). The original title is "The message of Leonardo: His relation to the birth of modern science" (Cf. Sarton, 1948, p. 188). See also Strelsky (1957, item 69). In Sarton (1937, pp. 99-100), he refers to what he calls the "experimental spirit" and says that "we may consider Leonardo da Vinci its first deliberate vindicator".

${ }^{10}$ The second of Sarton's two texts about Leonardo cited by Thackray and Merton. Published in 1952, it corresponds to item 8 of Katharine Strelsky's catalogue, cited in the preceding footnote. See also footnote 4, above.
} 
Lindberg with respect to Galen, Sarton examines the difficulties faced by the great Renaissance man, asserting that while he had no superstitions, he was unable to completely free himself of old prejudices.

In fact, Sarton presents the history of blood circulation in a way that reveals the difficulties encountered by those who might have discovered "the Truth" earlier. The list of observers, whose paths were blocked by the "gospel" according to Galen (and later Avicenna), includes names of scientists who lived the golden age of the search for truth, the Renaissance:

When I shut my eyes and evoke the past, I imagine that this great discovery was enclosed in a chest of which intelligent observers like Leonardo, Vesalius, Servetus or Columbus could have easily found the secret if they had set their hearts upon it, but they did not dare approach near enough because Prejudice sat on the lid. I can see those great men standing shyly around the coffer, mysteriously attracted by it, yet awed into impotence, while Truth was prisoner inside (Sarton, 1948, p. 9).

Regarding the "intelligent observers" who could have found a definitive explanation for blood circulation, Sarton appears to regret in particular the fact that even Leonardo da Vinci, "endowed with so much genius and originality, and had himself dissected a large number of bodies and examined very minutely many a heart [...] was subjugated by this intangible dogma" (Sarton, 1948, p. 9). Sarton goes so far as to assert that Leonardo had perceived the true explanation, but that the "invisible pores" imagined by Galen and Avicenna were too sacred to be contested. Leonardo, he believed, was "so completely dominated by the Galenic prejudice that he was not only able to see the invisible pores, but even to draw them. It would be difficult to think of a better example of the limitations of the genious" (Sarton, 1953a, p. 17). According to Sarton, it was prejudice that kept Leonardo from making the discovery about blood circulation. ${ }^{11}$ Thus, the way Sarton refers to Leonardo because of the discovery he did not make is illustrative of the importance he attributed to him in the history of science.

\footnotetext{
${ }^{11}$ The idea that the Galenic doctrine is responsible for the "aberrations", "limitations", "dogmatism" and "prejudices" of Leonardo is briefly and particularly well-described in Sarton (1930, p. xix). See also Sarton (1959, p. 87). In addition to the Galenic prejudice, Sarton also identifies 'Platonic prejudices': "From Plato, the Neoplatonists, and the Qabbala, he had inherited the idea of microcosm versus macrocosm [...] This misled him, as it had misled innumerable people before him, into all kinds of false analogies. Man's bones are like the earth's rocks; there is in him a lake of blood even as there are oceans; the tides of the sea are comparable to a man's pulse, the "circulation" of the blood in the body is like the circulation of water in the earth; hair and feathers are like the grass in meadows or leaves on the trees (Sarton, 1962, p.137). The influence of the Platonic prejudice on Leonardo is discussed in a similar way in Sarton (1953a, p.17).
} 
In the reviews written by Sarton regarding Leonardo, his assessment of the works is guided precisely by the interpretation that the organizers present with respect to Leonardo's 'non-discovery'.

Thus in his 1944 review, we read:

In order to measure the value of the Richter and MacCurdy collections for the historian of science, let us consider a crucial example, Leonardo's views on the circulation of the blood. Richter does not hesitate to say "Leonard had a clear conception of it" (his vol. 2, 105, note). That statement is as preposterous as it is dogmatic. The few extracts quoted by himself do not in the least justify it. MacCurdy does not dogmatize, but he gives us a much larger selection of anatomical and physiological items and enables us to reach truer conclusions (Sarton, 1944, pp. 185186).

In the review of Leonardo's works compiled by O'Malley and Saunders, Sarton highlights precisely Leonardo’s anatomy notebook, and asserts:

The main advantage of this publication for English-reading historians of science is the fact that all the drawings and the texts concerning them are grouped in systematic order [...] An introduction contains all the information relative to Leonardo's life, anatomical illustrations anterior to him, his anatomical achievements, his MSS [manuscripts], etc. Let us give an example; the best that one could choose is the conclusions on Leonardo's knowledge of the heart and the movement of the blood (Sarton, 1953, p. 65).

Sarton then cites a passage in which O'Malley and Saunders argue that Leonardo had no knowledge of blood circulation, and that, until 1500, his opinion was derived from the degraded view of the ancient wise man, Galen. The great praise of the book is due, above all, to his having shown Leonardo's limitations with respect to anticipating Harvey's discovery. $^{12}$

\section{Kuhn, Butterfield, and Sarton}

As we saw, in one of the few passages where he cited names responsible for the traditional historiography of science, Kuhn (1977, p. 148) refers to a tradition that extends "from Condorcet and Comte to Dampier and Sarton". According to him, this tradition

\footnotetext{
${ }^{12}$ He confirms this appreciation in Sarton (1957, pp. 174-175 and p. 294, note 4).
} 
viewed scientific advance as the triumph of reason over primitive superstition, the unique example of humanity operating in its highest mode. [...] the chronicles which this tradition produced were ultimately hortatory in intent, and they included remarkably little information about the content of science beyond who first made which positive discovery when. [...] Though I know it will give offense to some people whose feelings I value, I see no alternative to underscoring the point. Historians of science owe the late George Sarton an immense debt for his role in establishing their profession, but the image of their specialty which he propagated continues to do much damage even though it has long since been rejected (Kuhn, 1977, p. 148). ${ }^{13}$

In a long interview in 1995, when asked why he had not associated himself directly with Sarton at Harvard, Kuhn cited a significant divergence between them:

He [Sarton] certainly was a Whig historian and he certainly saw science as the greatest human achievement and the model for everything else. And it wasn't that I thought that it was not a great human achievement, but I saw it as one among several. I could have learned a lot of data from Sarton but I wouldn't have learned any of the sorts of things I wanted to explore" (Kuhn, 2000, p. 282).

Immediately following that comment, in a rapid assessment of the American academic environment in which he began his studies of the history of science, Kuhn highlights the discrepancy between his point of view and that of Sarton and a few other contemporaries. According to him, what they did was not "quite history; it was textbook history" (Kuhn, 2000, p. 282).

On the first page of Structure, Kuhn briefly describes this traditional historiography of science in these terms:

If science is the constellation of facts, theories, and methods collected in current texts, then scientists are the men who, successfully or not, have striven to contribute one or another element to that particular constellation. [...] And history of science becomes the discipline that chronicles both these successive increments and the obstacles that have inhibited their accumulation. Concerned with scientific development, the historian then appears to have two main tasks. On the one hand, he must determine by what man and at what point in time each contemporary scientific fact, law, and theory was discovered or invented. On the other, he must describe and explain the congeries of error, myth, and superstition that have inhibited the more rapid accumulation of the constituents of the modern science text (Kuhn, 1970, pp. 1-2).

\footnotetext{
${ }^{13}$ See also Kuhn (1977, p. 106).
} 
In his criticism of the older historiographies in The essential tension, Kuhn points to examples of works that he believed were changing the history of the scientific development in a significant way. Of particular interest to us here are his considerations regarding the work of Herbert Butterfield. For Kuhn, this (general) historian's book about the history of science, The origins of modern science, first published in 1949, contributed significantly to break from the misleading view of modern science as having emerged due to the new observations and methods. And when he highlights the importance of examining medieval science to understand the essential novelties of the $17^{\text {th }}$ Century, Kuhn points to Butterfield's "pioneering synthesis" as a reference on a path worth following (Kuhn, 1977, p. 109).

According to Kuhn (1977, p. 35, note 3), Butterfield, in his studies regarding the origins of modern science, "plausibly explained the main conceptual transformations of early modern science as 'brought about, not by new observations or additional evidence in the first instance, but by transpositions that were taking place inside the minds of the scientists themselves",14. However, while Butterfield may have written an "admirable" work (Kuhn, 1977, p. 35, note 3) and traced a better path for the historical analysis of science, he did not, in Kuhn's judgment, remain entirely faithful to this path throughout the work. Kuhn writes:

Butterfield's first four chapters plausibly explained the main conceptual transformations of early modern science [...] The next two chapters, "The Experimental Method in the Seventeenth Century" and "Bacon and Descartes", provided more traditional accounts of their subjects. Although they seemed obviously relevant to scientific development, the chapters which dealt with them contained little material actually put to work elsewhere in the book (Kuhn, 1977, p. 35, note 3).

In another reference, Kuhn's caveat is more specific. The object of his praise is no longer all of the first four chapters. Despite referring again to The origins of modern science as "admirable", Kuhn says that

One aspect of Butterfield's discussion has, in fact, helped to preserve the myths. The historiographic novelties accessible through his book are concentrated in chaps. 1,2, and 4, which deal with the development of astronomy and mechanics. These are, however, juxtaposed with

\footnotetext{
${ }^{14}$ The reference to Butterfield as an example of a "perceptive historian" appears already in Structure (Kuhn, 1970, p. 85). See also Kuhn (1957, p. 283).
} 
essentially traditional accounts of the methodological views of Bacon and Descartes, illustrated in application by a chapter on Willian Harvey (Kuhn, 1977, p. 131, note 2). ${ }^{15}$

The chapter about William Harvey to which Kuhn refers is Chapter 3. Kuhn claims it fails to provide a plausible explanation of the conceptual transformations at the beginning of modern science, and supports "essentially traditional accounts of the methodological views". It is worth asking at this point: what characteristics of Chapter 3 of The origins of modern science render it an "essentially" traditional account? Not surprisingly, they are the same ones that are present in Sarton's analysis regarding the discovery of blood circulation.

The first note in Butterfield's chapter on Harvey that calls our attention as being characteristic of a traditional history is the comparison between the development of knowledge beginning with the Renaissance and that which preceded it. In this aspect, Butterfield exalts the great advances in the art of observation, remembering that artists (Leonardo da Vinci, in particular) "were the first to cry out against mere subservience to authority - the first to say that one must observe the nature for oneself" (Butterfield, 1966, p. 51).

Much like Sarton, Butterfield exalted the discovery of blood circulation as the result of merit and the individual capacity of the discoverer to extricate himself from past tradition, remembering that Harvey would have declared that he "learned and taught anatomy, "not from books but from dissection"” (Butterfield, 1966, p. 61). In this evaluation, the historian emphasizes the role of Harvey's experimental method, which reveals an "extraordinarily modern flavour" (Butterfield, 1966, p. 62) and breaks definitively from the Galenic view. After presenting a synthesis of this view, he asserts:

Here we have a complex system of errors concerning which it has to be noted that the doctrine was not only wrong in itself, but, until it was put right, it stood as a permanent barrier against physiological advance - for, indeed, nothing else could be right. It is another of those cases in which we can say that once this matter was rectified the way lay open to a

\footnotetext{
${ }^{15}$ In his book about Butterfield, after referring to the above passage, Sewell (2005, p. 163) wrote: "In making these observations Kuhn was apparently unaware of their relevance to the problem of reconciling Butterfield's concept of technical history and an expository historiography based on his belief in providence. Butterfield's three ways or levels formulation had sought to distinguish these, but in the course of doing so he effectively integrated them". A discussion of this point is beyond the scope of this article, however.
} 
tremendous flood of further change elsewhere (Butterfield, 1966, pp. 54$55)$.

According to Butterfield (1966), Galen's dominance endured for a long time and extended over many thinkers - "even Leonardo da Vinci" (p. 55). In his analysis of the evolution leading to Harvey's discovery, Butterfield discusses the contributions of scientists who could have made the discovery but did not because they were overly influenced by Galen.

Until the seventeenth century, therefore, a curious mental rigidity prevented even the leading students of science from realising essential truths concerning the circulation of the blood, though we might say with considerable justice that they already held some the most significant evidence in their hands (Butterfield, 1966, p. 58, our emphasis).

Butterfield commented that the consolidated reception of Harvey's work took thirty to fifty years, "though his arguments would perhaps seem more cogent to us today than those of any other treatise that had been written up to this period" (Butterfield, 1966, p. 65). For Butterfield, what made the big difference was the experimental method:

Only now could one begin to understand respiration itself properly, or even the digestive and other functions. Given the circulation of blood running through the arteries and then back by the veins, one could begin to ask "what it carries, and why, how and where it takes up its loads [...]" Both in regard to methods and results, therefore, we seem to have touched something like the genuine scientific revolution at last. (Butterfield, 1966, pp. 65-66).

\section{Final considerations}

"For forty years the name of George Sarton has been practically synonymous with the history of science". The opening statement to Dorothy Stimson's preface to Sarton on the history of science, published in 1962, is still very expressive fifty years later but is not lacking in ambiguity. It was also in 1962 that Kuhn, with The structure of scientific revolutions, announced the emergence of a new history of science in response to an older history of science, which existed as an autonomous academic discipline thanks to, above all, the untiring work of Sarton. 
Thus, if Stimson's recognition of Sarton's contribution to the establishment of the field still carries weight, ${ }^{16}$ it is also true that such an assertion can now be challenged in light of the new conception of the history of science, which scarcely mentions the historical work of Sarton. ${ }^{17}$

As we can see, Butterfield maintains some traces of the history that Kuhn assessed as being traditional because of Butterfield's distorted view of the role of the experimental method in the Scientific Revolution (especially in the case of physiology). We should remember that Kuhn refers to physiology as being a field in which experimentation did not follow the Baconian model, but rather the classic model of Galen. ${ }^{18}$ It is also worth noting that, in one of his rare mentions of Leonardo da Vinci in his work, Kuhn (1977, p. 49) writes: “as Leonardo's career also indicates, instrumental and engineering concerns do not make a man an experimentalist".

The aspects that approximate Butterfield to Sarton are the same ones that distance him from Kuhn. The origins of modern science represents a step toward the new historiography, but, according to Kuhn, still has a foot in the traditional historiography. The characteristics of this historiography which Kuhn identifies in Butterfield can also be found in Sarton's historical account of the discovery of blood circulation. Thus, this episode seems to us to be a concrete example of Whig history ${ }^{19}$ not explicitly pointed out by Kuhn; an example that attests to the substantial difference between the "old" and the "new" historian of science. ${ }^{20}$

It is worth remembering at this point a passage by Sarton cited earlier in this article: "Many people misunderstand science, and hence one can hardly expect them to have a fair idea of its history." (Sarton, 1962, p. 102). Kuhn, on the other hand, throughout

\footnotetext{
${ }^{16}$ See, for example, Kuhn (1977, p. 148); Fichant (1969, p. 67) and Kragh (1989, p. 19).

${ }^{17}$ Helge Kragh (1987, pp. 18 and 198, note 43), for example, states that Sarton's view is, according to modern standards, "somewhat naive and surprisingly ahistorical", with reference to the judgment of Hall (1969) who, despite considering Sarton a man of great knowledge, admits that one must ask if he was in fact a historian. Kragh also cites Kuhn (1977, p. 148) for evidence of Sarton's supposedly ahistorical view. Sayili (2005) and Pyenson (2007) are among the few interpreters who recently sought to reaffirm the importance of Sarton's work as a historian.

${ }^{18}$ See Kuhn (1977, p. 136).

${ }^{19}$ Kuhn uses the expression "Whig", coined by Butterfield himself in 1931. As summarized by the author, Whig history, or "whiggism" is "the tendency in many historians to write on the side of Protestants and Whigs, to praise revolutions provided they have been successful, to emphasise certain principles of progress in the past and to produce a story which is the ratification if not the glorification of the present" (Butterfield, 1973, p. 9).

${ }^{20}$ Cf. Pinto de Oliveira (2012). In a forthcoming paper, "Carnap, Kuhn, and the history of science: A reply to Thomas Uebel”, Pinto de Oliveira relates Carnap (and Reichenbach) to Sarton's 'old historiography'.
} 
Structure, suggests the opposite: that if one does not have a good understanding of the history of science, one will not understand science itself.

To conclude, we cite two passages by Sarton which, like other more diffuse passages cited in the text, can be seen as 'negative images' of Kuhn's normal science:

Neither do I mean to imply that all the schoolmen were dunces. Far from that, not a few were men of amazing genius, but their point of view was never free from prejudice; it was always the theological or legal point of view; they were always like lawyers pleading a cause; they were constitutionally unable to investigate a problem without reservation and without fear. Moreover, they were so cocksure, so dogmatic (Sarton 1948, p. 77).

It has often been repeated that anatomy was neglected in the Middle Ages because of religious prejudices. Anatomy was not completely neglected, and dissections, even human dissections, were made from time to time, but these dissections were few and they were not made with sufficient application nor with sufficient freedom of thought. The shackles of the medieval anatomists were less religious than scholastic. Medical men had not acquired the habit of seeing with their eyes open without prejudices. Indeed, they were so much dominated by older masters such as Galen and Avicenna that they were not only blind to reality but able to see things which were not there at all; Galen's words were more convincing to them than reality itself! It is a bit difficult for us to imagine such a state of mind, though it has not yet completely disappeared. The renovation of anatomy was finally accomplished by men who were good observers, had dexterous hands and sharp eyes, and were not inhibited by prejudices (Sarton, 1962, p. 134).

Kuhn positions himself against negative assessments of this type when he speaks of normal science. Long before Structure and the concept of paradigm, as John Preston points out (2008, p. 5), Kuhn already viewed these "prejudices" or "points of view", "principles" or "conceptual frameworks" not as impediments, but as essential to the development of science.

And Kuhn speaks of "dogmas", as well. In "The Function of Dogma in Scientific Research" 21 , he writes:

At some point in his or her career every member of this Symposium [Oxford, 1961] has, I feel sure, been exposed to the image of the scientist

\footnotetext{
${ }^{21}$ Kuhn expressed dissatisfaction with this text and did not want it included in the collections of his essays (Cf. Kuhn, 2000, p. 2, note 1). However, he certainly had no objections to the first and last paragraphs, which we cite here to conclude the article.
} 
And:

as the uncommitted searcher after truth. He is the explorer of nature -- the man who rejects prejudice at the threshold of his laboratory, who collects and examines the bare and objective facts, and whose allegiance is to such facts and to them alone. [...] To be scientific is, among other things, to be objective and open-minded (Kuhn, 1963, p. 347).

\begin{abstract}
Almost no one, perhaps no one at all, needs to be told that the vitality of science depends upon the continuation of occasional tradition-shattering innovations. But the apparently contrary dependence of research upon a deep commitment to established tools and beliefs receives the very minimum of attention. I urge that it be given more. Until that is done, some of the most striking characteristics of scientific education and development will remain extraordinarily difficult to understand (Kuhn, 1963, p. 369).
\end{abstract}

\title{
References
}

Butterfield, H. (1966). The origins of modern science 1300-1800. New York: The Free Press (First published 1949).

Butterfield, H. (1973). The Whig interpretation of history. Harmondsworth, England: Penguin (First published 1931).

Fichant, M. (1969). Sur l'histoire des sciences. In M. Pécheux \& M Fichant, Sur l'histoire des sciences. Paris: Maspéro.

Hall, A. R. (1969). Can the history of science be history? British Journal for the History of Science, 4, 207-220.

Kragh, H. (1989). An introduction to the historiography of science. Cambridge: Cambridge University Press.

Kuhn, T.S. (1957). The Copernican revolution: Planetary astronomy in the development of western thought. Cambridge: Harvard University Press.

Kuhn, T.S. (1963). The function of dogma in scientific research. In A. C. Crombie (Ed.), Scientific change: Historical studies in the intellectual, social and technical conditions for scientific discovery and technical invention, from Antiquity to the present (pp. 347369). London: Heinemann Educational Books.

Kuhn, T. S. (1970). The structure of scientific revolutions, Chicago: University of Chicago Press (First published 1962).

Kuhn, T. S. (1977). The essential tension. Chicago: The University of Chicago Press.

Kuhn, T. S. (2000). The road since Structure. Chicago: The University of Chicago Press.

Lindberg, D. (2007). The beginnings of western science: The European scientific tradition in philosophical, religious, and institutional context. Chicago: The University of Chicago Press.

Pinto de Oliveira, J.C. (2012). Kuhn and the genesis of the "new historiography of science". Studies in History and Philosophy of Science. 43, 115-121.

Pinto de Oliveira, J.C. (forthcoming). Carnap, Kuhn, and the history of science: A reply to Thomas Uebel.

Preston, J. (2008). Kuhn's The Structure of Scientific Revolutions: A reader's guide. London: Continuum.

Pyenson, L. (2007). The passion of George Sarton. A modern marriage and its discipline. Philadelphia: American Philosophical Society. 
Sarton, G. (1919). Une encyclopédie léonardesque. Raccolta Vinciana. 10, 235-242.

Sarton, G. (1927). Introduction to the history of science. (Vol. 1) Baltimore: Williams and Wilkins.

Sarton, G. (1930). Preface. In J.P. McMurrich, Leonardo da Vinci, the anatomist: 14521519 (pp. Xv-Xx). Baltimore:Williams and Wilkins Co.

Sarton, G. (1936). The study of the history of science. Cambridge, Massachusetts: Harvard University Press.

Sarton, G. (1937). The history of science and the new humanism. Cambridge: Harvard University Press (First published 1931).

Sarton, G. (1944). Review of J.P. Richter e I. A. Richter: The literary works of Leonardo da Vinci; and E. MacCurdy: The notebooks of Leonardo da Vinci, Isis, 35, 2, 184187.

Sarton, G. (1948). The life of science. Essays in the history of civilization. New York: Henry Schuman.

Sarton, G. (1950). Boyle and Bayle. The sceptical chemist and the sceptical historian. Chymia, 3, 155-189.

Sarton, G. (1953a). Léonard de Vinci, ingenieur et savant. In L. Febvre et al., Léonard de Vinci \& l'expérience scientifique au seizième siècle (pp. 11-22). Paris: Presses Universitaires de France.

Sarton, G. (1953b). Review of C. D. O’Malley e J.B. de C.M. Saunders: Leonardo da Vinci on the human body, Isis, 44, 1/2, 65-66.

Sarton, G. (1954). Galen of Pergamon. Kansas: University of Kansas Press.

Sarton, G. (1957). Six wings: Men of science in the Renaissance. Bloomington, Indiana: Indiana University Press.

Sarton, G. (1959). Science in Renaissance. In J.W. Thompson et al, The civilization in the Renaissance (pp. 75-95). New York: Frederick Ungar Publishing Co. (First published 1929).

Sarton, G. (1962). Sarton on the history of science. Essays by George Sarton. Ed. by Dorothy Stimson. Cambridge, Massachusetts: Harvard University Press.

Sayili, S. (2005). George Sarton and the history of science. Foundation for Science, Technology and Civilization, 1-26. http://www.muslimheritage.com/uploads/Sarton.pdf. (Accessed 26 Februrary 2013).

Sewell, K. (2005). Herbert Butterfield and the interpretation of history. N. York: Palgrave Macmillan.

Stimson, D. Preface. In Sarton, 1962.

Strelsky, K. (1957). Bibliography of the publications of George Sarton. Isis, 48, 3, The George Sarton Memorial Issue, 336-350.

Thackray, A.; Merton, R. (1972). On discipline building: The paradoxes of George Sarton. Isis, 63, 4, 472-495. 